\title{
АКТУАЛЬНЫЕ ВОПРОСЫ ЦИФРОВИЗАЦИИ ЭКОНОМИКИ РОССИЙСКОЙ ФЕДЕРАЦИИ
}

\section{(c) 2019 Камынина Надежда Ростиславовна}

кандидат технических наук, доцент

доцент кафедры земельного права и государственной регистрации недвижимости

Московский государственный университет геодезии и картографии

105064, Москва, Гороховский пер., 4

E-mail: kamyninan@gmail.com

В статье описаны ключевые аспекты цифровизации экономики РФ, аккумулированы проблемы и перспективы реализации цифровизации в РФ, а также выделен ракурс цифровизации для повышения качества государственного управления.

Ключевые слова: цифровая экономика, эффекты, перспективы развития, качество государственного управления.

В настоящее время развитие любой страны определяется уровнем цифровизации ее экономики. При становлении цифровой экономики происходит трансформация традиционных форм экономических отношений в цифровые, однако, экономистами-теоретиками еще не выработано единое мнение относительно степени влияния уровня цифровизации на величину ВВП в силу предполагаемости возможных мультипликативных и кросс-отраслевых эффектов. Учитывая динамику цифровых технологий и их применение, потенциал цифровой экономики для повышения благосостояния страны очевиден. Такой подход помогает формировать приоритеты государственной политики и включать более конкретные и продуманные мероприятия, что, в свою очередь, важно для повышения каче-

ства государственного управления как одной из первоочередных стратегических целей РФ.

По мнению авторитетных экспертов, цифровая экономика представляется экономической институциональной средой, где цифровые технологии направлены на обеспечение потребностей государства, повышение результативности бизнеса и благосостояния населения [10].

В Международном рейтинге «Индекс цифрового развития стран» по состоянию на 2017 год Россия занимает 39 место (табл.1) [11].

Международный опыт цифровизации демонстрирует, что государство активно участвует в трансформационных процессах, получая экономические и социальные эффекты. В настоящее время в США доля цифровой экономики составляет 10,9\%, в Китае -10\%, в ЕС -8,3\% [2,9].

Таблица 1. Рейтинг «Индекс цифрового развития стран»

\begin{tabular}{|l|c|c|}
\hline \multicolumn{1}{|c|}{ Страна } & Индекс & Ранг \\
\hline Норвегия & 3,79 & 1 \\
\hline Швеция & 3,79 & 2 \\
\hline Швейцария & 3,74 & 3 \\
\hline Дания & 3,72 & 4 \\
\hline Финляндия & 3,72 & 5 \\
\hline Сингапур & 3,69 & 6 \\
\hline Южная Корея & 3,68 & 7 \\
\hline Великобритания & 3,67 & 8 \\
\hline Гонконг & 3.66 & 9 \\
\hline США & 3,61 & 19 \\
\hline$\ldots \ldots$ & & 39 \\
\hline Россия & 2,44 & \\
\hline
\end{tabular}

Источник. Chakravorti B., Chaturved R. Sh. Digital Planet 2017. How Competitiveness and Trust in Digital Economies Vary Across the World [11, c. 21] 
Зарубежный опыт создания цифровой экономики, например, в Германии, являющейся автором проекта «Индустрия 4.0», показывает, что государство не занимает центральное место в структуре финансирования цифровых проектов, но создает правила ее функционирования, развития фундаментального образования, стимулирования исследований и т.п. [8,9].

В Южной Корее и Японии цифровизация происходит на базе таких организаций, как LG, Samsung, Sony, SoftBank, Toshiba, Toyota, где можно выделить проекты интернет-торговли, создания экосистем (Rakuten) и интернет-мессенджеров (Line, Kakao). В США объем цифровой экономики достаточно высок, а объем ВВП объясняется интенсивным инвестированием в цифровизацию, в том числе государственным. Китай, несмотря на то, что относится к развивающимся странам, занимает второе место после США, и в котором также выявлены и внедрены перспективные цифровые решения, разработаны собственные проекты «Alibaba» и «Huawei». Широкое распространение среди населения Китая имеет интернет-ритейл, активно используются возможности онлайн-экосистем и цифровой банкинг [9].

В России [8] вклад цифровой экономики в ВВП страны в настоящий момент демонстрирует возвращение тенденций к росту после небольшого снижения в 2015 году (рисунок 1). Вместе с тем по прогнозам цифровизация экономики России может увеличить ВВП страны к 2025 году на 4,1-8,9 трлн. руб., от 19 до 34\% роста ВВП [9].

По мнению экспертов, темпы роста цифровой экономики в РФ еще отстают от темпов в странах-лидерах. В частности, по мнению экспертной группы Digital McKinsey [9], цифровизация является источником долгосрочного экономического роста за счет: оптимизации производственных и логистических операций; повышения эффективности рынка труда; увеличения производительности оборудования; по- вышения эффективности НИОКР и разработки новых продуктов; снижения расхода ресурсов и производственных потерь.

Цифровизация способна повысить качество жизни населения благодаря новым возможностям трудоустройства, росту покупательской способности, росту вовлеченности и социального участия граждан в управлении социально значимыми процессами, повышению комфортности проживания в городах, расширению доступности социальных благ, удобству цифровых сервисов и цифровых госуслуг, национальной, экономической и общественной безопасности [8].

Миссия развития цифровой экономики в России - повысить качество жизни, обеспечить конкурентоспособность страны и национальную безопасность. Цель цифровизации в перспективе 15-20 лет - войти в группу лидирующих экономик мира за счет цифровых преобразований традиционных отраслей и развития самостоятельной и конкурентоспособной цифровой индустрии [6].

В России в соответствии с программой «Цифровая экономика РФ» в ближайшее время предполагается создать необходимые условия для масштабного развития цифровой экономики. Программа устанавливает следующие целевые результаты:

- Формирование институциональных и инфраструктурных условий для развития высокотехнологических бизнесов.

- Создание экосистемы цифровой экономики РФ на основе цифрового формата данных, используемых в социально-экономической деятельности общества.

В экосистеме цифровой экономики предполагается сформировать следующие уровни:

- уровень взаимодействия потребителей и поставщиков;

- уровень формирования компетенций для развития экономических отраслей;

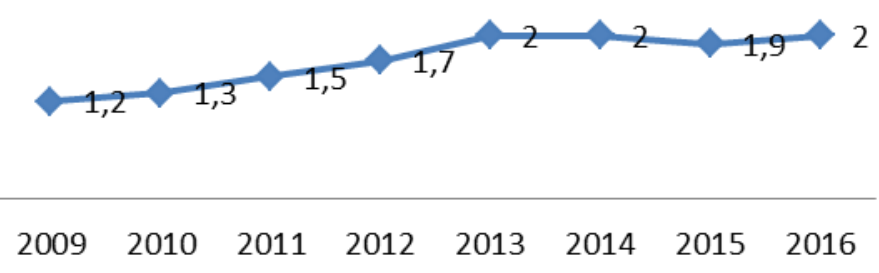

Puc. 1 Доля цифровой экономики в ВВП РФ [9] 
- уровень средовых условий: нормативно-правовое регулирование, информационные инфраструктура и безопасность, кадры [7].

Для формирования цифровой экономики в РФ планируется использовать цифровые технологии больших данных, инновационные производственные технологии, нейротехнологии, искусственный интеллект, новые производственные технологии, системы распределенного реестра и т.п.[7,9].

По результатам исследований, проведенных ПАО «Ростелеком» [4], основными глобальными трендами в области цифровизации являются мобильный интернет, искусственный интеллект, электронная коммерция, при этом прорывными и устойчивыми трендами называются блокчейн и визуальная идентификация личности. Вместе с тем РФ в общемировом рейтинге развития трендов цифровизации занимает 11 место [10].

По результатам опроса в рамках исследования [2] о полученных результатах от внедрения цифровых технологий в организациях предпринимательской сферы в числе значимых эффектов цифровизации выделяются: увеличение выручки, повышение скорости производства продукции и предоставления услуг, повышение прозрачности деятельности, улучшение качества продукции и услуг, снижение ресурсоемкости, а также получение косвенных эффектов в сопряженных сферах деятельности компаний. По мнению респондентов, наибольшее влияние оказывают интернет вещей, автоматизация производства, мобильные технологии и кросс-канальные коммуникации, технологии виртуализации, удаленный доступ и т.п., цифровое проектирование и моделирование.

В исследованиях [2,8,9] сформулированы основные проблемы внедрения цифровизации, включающие: неправильно поставленные цели и задачи проекта цифровизации, некорректная исходная информация об объекте внедрения цифровых решений, ошибки в планировании видов и последовательности работ, технологическая некомпетентность пользователей, экономическая неопределенность в стране, волатильность рубля, нормативные ограничения, отсутствие стандартов по применению цифровых технологий, отсутствие специальных мер государственной поддержки использования цифровых технологий компаниями, цифровое неравенство регионов [2].

По мнению экспертов [9], цифровая эконо- мика позволит улучшить деловой и инвестиционный климат благодаря повышению доступности и эффективности государственных услуг при регистрации, сертификации и аккредитации и т.п., развитию экосистемы бизнес-сервисов, повышению прозрачности условий ведения бизнеса, формированию единых технологических платформ для всех участников цифровой экономики.

Для успешного развития цифровой экономики, по мнению исследователей, необходимо:

- Создать равную конкуренцию, так как основной движущей силой создания условий для развития цифровой экономики выступает предпринимательский сектор; государство в данном случае является только инициатором и организатором создания цифровой инфраструктуры.

- Сформировать общие технологические платформы, обеспечивающие синхронный переход заинтересованных организаций на цифровые отношения.

- Выработать документы правого регулирования, так как цифровой формат предполагает новые субъекты и объекты правоотношений, специфические права, обязанности и ответственность.

- Обучить и переобучить ИТ-специалистов, работников и служащих коммерческих предприятий и организаций, государственных учреждений, а также население страны.

- Информировать потребителей и популяризировать цифровые продукты и их применение.

- Обеспечить уверенность всех экономических субъектов и пользователей в безопасности.

- Выработать новые технологические решения, причем с активным привлечением государства.

Ожидаемые результаты внедрения цифровой экономики в ракурсе комплексной полезности для общества - это: удобные сервисы и режимы коммуникаций между гражданами и государством; создание условий для развития общества знаний в РФ; повышение благосостояния и качества жизни граждан, а также доступности и качества товаров и услуг; увеличение степени информированности и цифровой грамотности; улучшение доступности и качества государственных услуг для граждан, и в целом безопасности как внутри страны, так и за ее пределами [4].

Цифровизация является базисом для повы- 
шения качества государственного управления. По мнению экспертов [5], цифровизация госуправления предполагает: перевод внутренних процессов и межведомственных взаимодействий в полностью цифровой формат, формирование обратной связи с государственными и социальными службами, сбор и анализ больших массивов данных для принятия эффективных решений, что важно для повышения качества государственного управления.

Исходя из этого, можно сделать вывод, что цифровизация имеет потенциал повышения качества госуправления через увеличение удовлетворенности заинтересованных сторон [1,3,5], что определяет необходимость разработки концептуальной платформы цифровизации государственного управления на основе модели повышения качества государственного управления.

Таким образом, цифровизация экономики
РФ направлена на достижение технологических, экономических и социальных эффектов, позволяющих обеспечить стране высокий уровень развития и более высокую конкурентную позицию на мировом рынке.

Технологии и мероприятия цифровизации приобретают особое значение не только для предпринимательской среды, социальных сфер, но и для повышения качества государственного правления недвижимым имуществом организаций (НИО). Следовательно, при формировании цифровых проектов в госуправлении НИО необходимо разработать концептуальную платформу цифровизации для повышения качества государственного управления НИО. Применение прогрессивных методов управления качеством при цифровизации госуправления НИО позволит обеспечить достижение высокого уровня благосостояния и экономический рост страны в целом.

\section{Библиографический список}

1. Горбашко E. А. Повышение качества управления на основе менеджмента качества // Стандарты и качество. 2009. № 3. С. $88-89$.

2. Доклад «Цифровая экономика: глобальные тренды и практика российского бизнеса»/под ред. Д.С. Медовникова. [Электронный ресурс]. Нац. исслед. ун-т Высшая школа экономики». Москва. 2017.121 с.- URL: https://imi.hse.ru/pr2017_1 (дата обращения: 19.10.2018)

3. Леонова Т.И. Оценка качества деятельности государственных органов / В.Г. Куганов, Т.И. Леонова, А.В. Лях. // Проблемы современной экономики. 2013. № 4 (48). С.217-228.

4. Мониторинг глобальных трендов цифровизации: отчет об исследовании // ПАО «Ростелеком», 2018. 30 с.URL: https://www.company.rt.ru/projects/digital_trends/2018.pdf (дата обращения: 10.10.18)

5. Окрепилов В.В. Повышение качества государственных услуг посредством внедрения систем менеджмента качества / В.В. Окрепилов // Теория и философия хозяйства. 2012. № 6. С. 9-12.

6. Петров М., Буров В., Шклярук М., Шаров А. Государство как платформа. (Кибер) Государство для цифровой экономики. Цифровая трансформация. [Электронный ресурс].- Москва. Центр стратегических разработок.- Апрель, 2018.- 52 с.- URL:: https://www.csr.ru/wp-content/uploads/2018/05/GOSUDARSTVO-KAKPLATFORMA_internet.pdf. (дата обращения: 10.10.2018)

7. Программа «Цифровая экономика Российской Федерации»: распоряжение Правительства Российской Федерации от 28 июля 2017 года № 1632-p.- URL: http://static.government.ru/media/files/9gFM4FHj4PsB79I5v7 yLVuPgu4bvR7M0.pdf (дата обращения: 09.10.18)

8. Россия онлайн: четыре приоритета для прорыва в цифровой экономике / Степаненко А., Банке Б., Бутенко В. [и др.]. [Электронный ресурс].-The Boston Consulting Group.-Октябрь, 2017. - 28 с.-URL: http://imagesrc.bcg.com/Images/Russia-Online_tcm27-178074.pdf. (дата обращения: 08.10.2018)

9. Цифровая Россия: новая реальность / Клинцов В., Аптекман А. [и др.]. [Электронный ресурс].-McKinsey\&Company.-Июль, 2017.- 133 c.-URL: https://www.mckinsey.com/ru/our-insights (дата обращения: 09.10.18).

10. Цифровая экономика: краткий статистический сборник / Г.И. Абдрахманова, Л. М. Гохберг, А.В. Демьянова и др.; Нац. исслед. ун-т Высшая школа экономики».- М.: НИУ ВШЭ, 2018.-96 c._URL: https://issek.hse.ru/ data/2018/07/27/1152150310/ice2018kr.PDF (дата обращения 18.10.18).

11. Chakravorti B., Chaturved R. Sh. Digital Planet 2017. How Competitiveness and Trust in Digital Economies Vary Across the World.- The Fletcher School, Tufts University.-July, 2017. - 70 p.- URL: https://sites.tufts.edu/ digitalplanet/files/2017/05/Digital_Planet_2017_FINAL.pdf (дата обращения: 08.10.2018) 